\title{
From pilot to program: Scaling up the Kenya Adolescent Reproductive Health Project
}

\author{
Humphres Evelia \\ Population Council \\ Japheth Nyambane \\ Harriet Birungi \\ Population Council \\ Ian Askew \\ Population Council \\ Rikka Trangsrud
}

See next page for additional authors

Follow this and additional works at: https://knowledgecommons.popcouncil.org/departments_sbsr-rh

Part of the Family, Life Course, and Society Commons, and the International Public Health Commons How does access to this work benefit you? Let us know!

\section{Recommended Citation}

Evelia, Humphres, Japheth Nyambane, Harriet Birungi, Ian Askew, Rikka Trangsrud, Eva Muthuuri, Irene Chaami, Agnes Odawa, Lucy Musyoka, Susan Mutungi, Margaret Githuiya, and Joan Omuruli. 2008. "From pilot to program: Scaling up the Kenya Adolescent Reproductive Health Project," FRONTIERS Final Report. Washington, DC: Population Council. 


\section{Authors}

Humphres Evelia, Japheth Nyambane, Harriet Birungi, Ian Askew, Rikka Trangsrud, Eva Muthuuri, Irene Chaami, Agnes Odawa, Lucy Musyoka, Susan Mutungi, Margaret Githuiya, and Joan Omuruli 


\title{
From Pilot to Program: Scaling up the Kenya Adolescent Reproductive Health Project
}

\author{
FRONTIERS, Population Council \\ Humphres Evelia \\ Japheth Nyambane \\ Harriet Birungi \\ Ian Askew \\ PATH \\ Rikka Trangsrud \\ Eva Muthuuri \\ Irene Chaami \\ Ministry of Education \\ Agnes Odawa \\ Ministry of Health \\ Lucy Musyoka \\ MGSCSS \\ Susan Mutungi \\ Ministry of Youth and Sports \\ Margaret Githuiya \\ Joan Omuruli
}

May 2008

This study was funded by the United States Agency for International Development (USAID) under the terms of Cooperative Agreement Number HRN-A-00-98-00012-00 with Population Council. The opinions expressed herein are those of the authors and do not necessarily reflect the views of USAID.

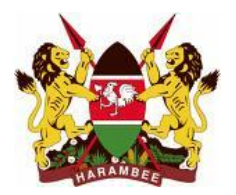


(C) 2008 The Population Council, Inc.

Suggested citation: Evelia, Humphres, Japheth Nyambane, Harriet Birungi, Ian Askew, Rikka Trangsrud, Eva Muthuuri, Irene Chaami, Agnes Odawa, Lucy Musyoka, Susan Mutungi, Margaret Githuiya, and Joan Omuruli. 2008. "From pilot to program: Scaling up the Kenya Adolescent Reproductive Health Project," FRONTIERS Final Report. Washington, DC:

Population Council.

Any part of this publication may be reproduced without permission for limited distribution provided it is distributed without charge and the Population Council is acknowledged as the source. The Population Council would appreciate receiving a copy of any materials in which the text is used. 


\section{TABLE OF CONTENTS}

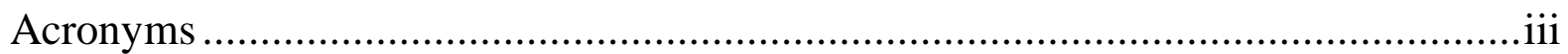

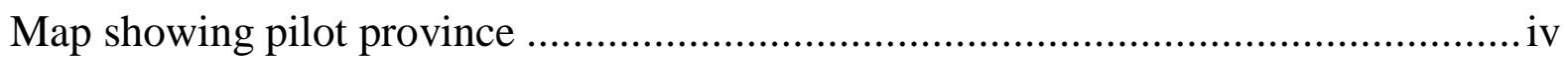

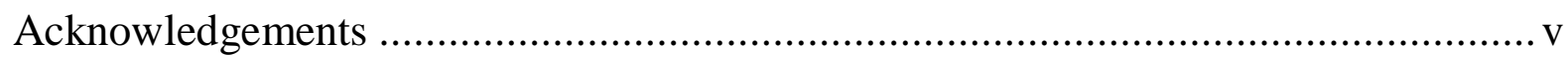

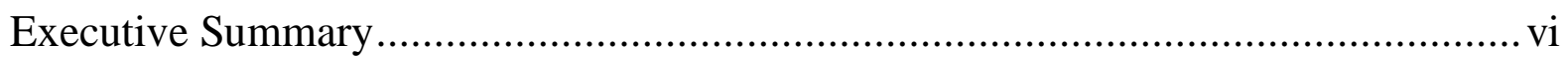

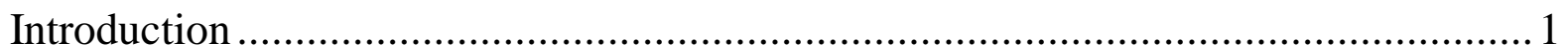

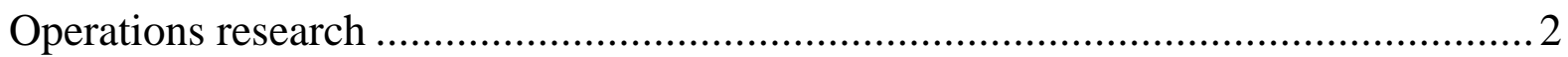

Intervention two: Meeting the information and service needs of sexually active

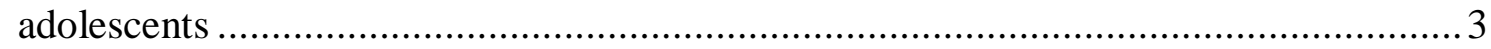

Intervention three: Educating in-school adolescents................................................... 4

Key highlights of the pilot phase ............................................................................ 4

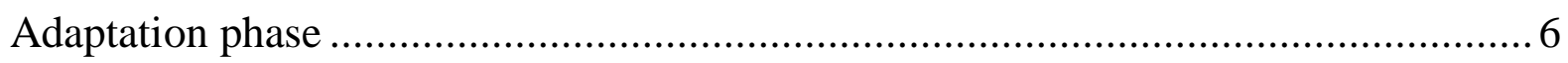

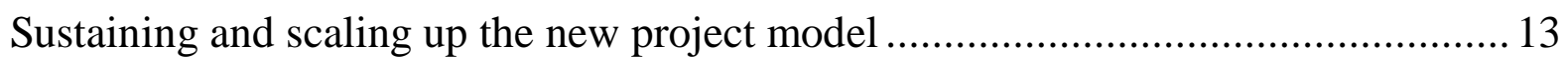

Government input in expansion and utilization of the model ......................................... 16

Replicating KARHP in other Provinces ............................................................... 18

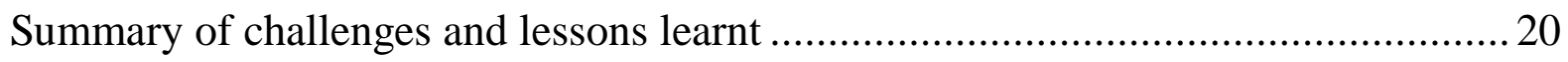

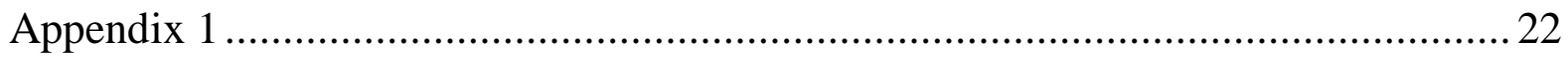




\section{ACRONYMS}

ASRH Adolescent Sexual and Reproductive Health

DEO District Education Officer

AEO Area Education Officer

TAC Teacher Advisory Centre

G\&C Guidance and Counseling

$\mathrm{MOH} \quad$ Ministry of Health

MGSCSS Ministry of Gender Spots, Culture and Social Services

MOE Ministry of Education

MOYA Ministry of State for Youth Affairs

KARHP Kenya Adolescent Reproductive Health Project

HIV Human Immunodeficiency Virus

AIDS Acquired Immune disease Syndrome

USAID United States Agency for International Development

PATH Program for Appropriate Technology in Health

STI Sexually Transmitted Infections

DHMT District Health Management Team

PHMT Provincial Health Management Team

BOG Board of Governors

SMC School Management Committees

APHIA AIDS Population and Health Integrated Assistance Program 
MAP SHOWING PILOT PROVINCE

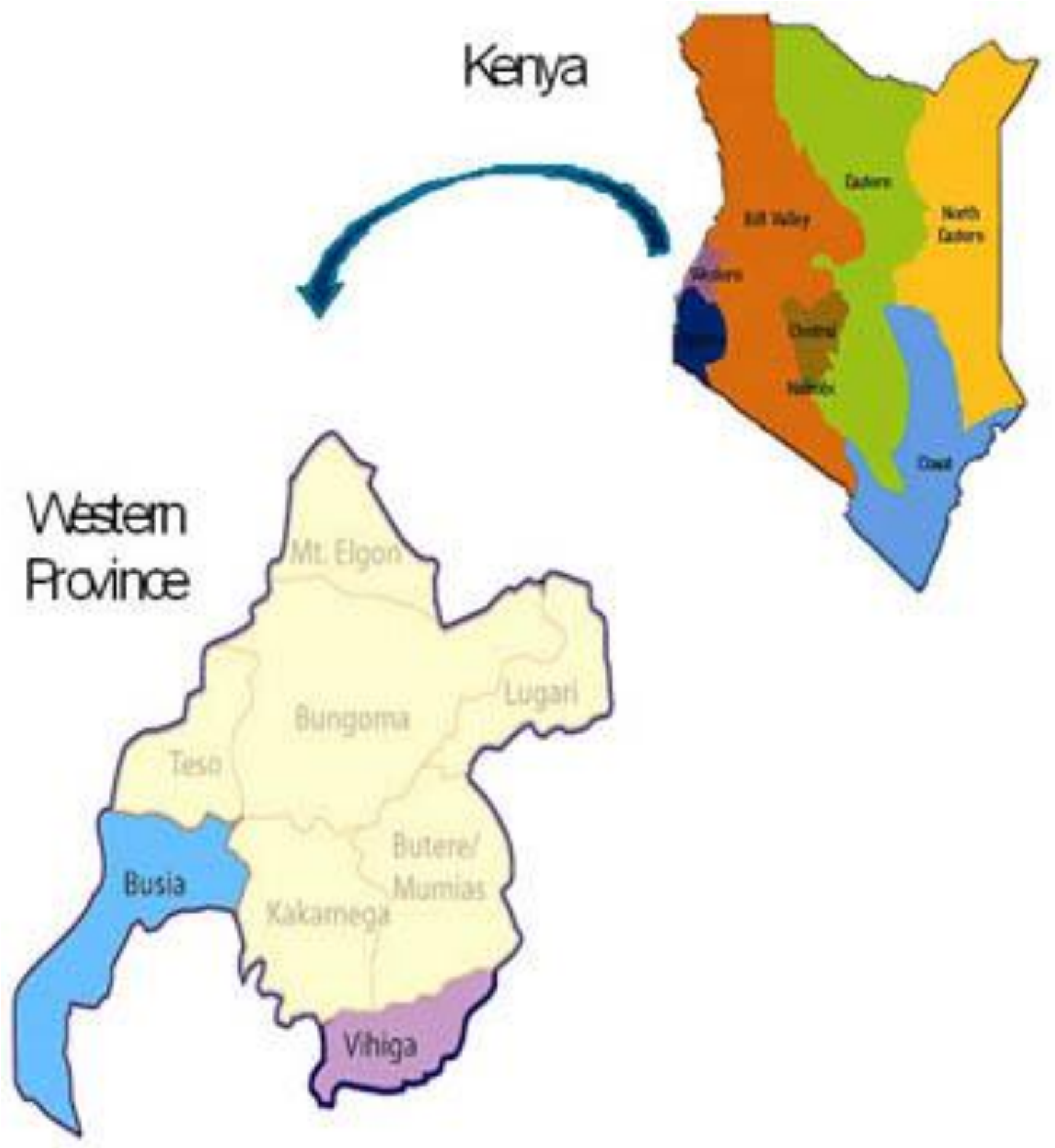




\section{ACKNOWLEDGEMENTS}

The authors would like to acknowledge and thank the following people who have all played a crucial role in developing and implementing this project. At the national level, Dr. Kibaru, Dr. Godia, Dr. Lucy Musoka, Dr. Charity Ndwiga, and Ann Gatitu from the Division of Reproductive Health, Ministry of Health; Agnes Odawa from the Ministry of Education, and Anne Ambwere, and Susan Mutungi from the Department of Social Services, Ministry of Gender, Sports, Culture and Social Services, Margaret Githuiya and Joan Omuruli from Ministry of Youth and Sports, all played crucial roles in ensuring that the project was designed to meet the needs and organizational requirements of their individual ministries. We would like to acknowledge the support and active involvement of all the ministry officials at provincial, district divisional and location levels who tirelessly participated in one way or the other in ensuring the success of KARHP.

Special thanks to Winnie Osulah, Ken Kibisu, Penninah Muringa and Stephanie Martin for the day to day running and coordination of KARHP activities in different provinces. Their invaluable contribution ensured that the interventions were accepted, implemented and monitored as per plan and schedule. The authors would like to acknowledge Caroline Njue from Population Council. And finally, the project would not have been possible without the commitment, energy and time contributed by all the teachers, medical staff, Community Development Assistants, Peer Educators and community leaders who implemented the project activities. 


\section{EXECUTIVE SUMMARY}

In 1999, the Population Council's Frontiers in Reproductive Health (FRONTIERS) Program and the Program for Appropriate Technology in Heath (PATH) collaborated with three Government of Kenya ministries - the Ministry of Education (MOE), the Ministry of Health (MOH), and the Ministry of Gender, Sports, Culture and Social Services (MGSCSS), to design and implement the Kenya Adolescent Reproductive Health Project (KARHP) with the following goals:

- To improve knowledge about reproductive health and encourage a responsible and healthy attitude towards sexuality among adolescents;

- To delay the onset of sexual activity among younger adolescents;

- To decrease risky behaviors among sexually active adolescents.

Interventions implemented by each ministry were piloted in communities of Vihiga and Busia districts in Western Province over a period of 30 months. The MGSCSS addressed the sociocultural sensitivity of adolescent sexual and reproductive health (ASRH) within communities by improving support and promoting dialogue around this topic among parents, leaders and adolescents. The MOE educated in-school adolescents about reproductive, sexual health and other issues through a life-skills curriculum. The $\mathrm{MOH}$ provided information and services, primarily to sexually active adolescents, through developing adolescent-friendly services.

Key findings from the pilot project showed that the three ministries could successfully implement these interventions with high participation among parents and youth. The evaluation showed that parent to child communication increased significantly, onset of sexual activity was somewhat delayed, there was a reduction in the mean number of sexual partners, and reduced incidences of sexual violence reported. There was increased awareness about contraceptive methods, especially condoms, pills and injectables, and the community and school-based interventions emphasized abstinence. Condom use for dual prevention of STIs and pregnancy became better known among adolescents as did awareness of specific STIs among all adolescents. The interventions reinforced disapproval of premarital sex and childbearing.

The positive results of the pilot phase prompted expansion of KARHP throughout the two pilot districts through a 20 -month period (2003 to 2005) of adaptation and institutionalization. The piloted materials and tools were revised, inter-sectoral committees set up at several levels of government, and cost-effective activities identified for institutionalization by each ministry. These activities were then scaled up throughout all districts in Western Province over a period of 12 months (June 2005 to May 2006). Funding throughout was provided by USAID/PEPFAR.

The scaling up experience and impact led to a 13-month phase of replication in Eastern and Nyanza provinces (June 2006 to May 2007), during which KARHP was introduced into two pilot districts in each province, followed the next year by expansion to the remaining districts during the second year. From June 2007 to May 2008, KARHP was further replicated in Nairobi and Central Province by the three ministries, using the same 2-phase strategy, with technical support from FRONTIERS, financial support from USAID and in collaboration with APHIA. 


\section{INTRODUCTION}

In 1999, FRONTIERS teamed with PATH and three government ministries (Education, Health, and Gender, Sports, Culture and Social Services) to develop and implement a multi-sectoral pilot project to address adolescent reproductive health and HIV prevention in two districts: Vihiga and Busia of Kenya's Western Province. At the time of the project's initiation, there were no systematic reproductive health education programs for in- and out-of-school adolescents. Providing SRH information and services to adolescents was then controversial, due to the belief that sexuality education and contraceptive services would lead to promiscuity among adolescents. The Kenya Adolescent Reproductive Health Project (KARHP) was launched to:

- Improve knowledge about reproductive health and encourage a responsible and healthy attitude towards sexuality among adolescents;

- Delay the onset of sexual activity among younger adolescents; and

- Decrease risky behaviors among sexually active adolescents.

KARHP was designed around the operations of three ministries at the district level. Each ministry took a lead in implementing an intervention that addressed a particular aspect of adolescent sexual reproductive health. The three interventions developed focused on:

- Creating a supportive environment within which information and services could be delivered by working directly with the local communities;

- Meeting adolescents' reproductive health information and service needs by increasing access within health facilities; and

- Educating in-school adolescents about sexual and reproductive health within a framework of information about life-skills and development.

The interventions were implemented through existing governmental structures, networks and systems. This report gives an overview of nine years of implementing KARHP (1999 - 2008) and describes the four stages of piloting and expansion that the program has undergone:

- A 30-month operations research phase;

- A 20-month adaptation phase

- A 12-month scale-up phase;

- A 13- month replication phase. 


\section{OPERATIONS RESEARCH}

KARHP was first piloted as an Operations Research (OR) project between 1999-2003 in two districts, Vihiga and Busia, in Western Province. During this phase, three interventions were tested over an 18-month period using a quasi-experimental design to compare their relative effect of key outcome indicators. One intervention sought to address the sensitivity of adolescent sexual and reproductive health by working with communities to create a supportive environment within which the educational and service delivery activities could be implemented. A second intervention addressed adolescents' sexual and reproductive health information and service needs, primarily of sexually active adolescents by increasing their access to health facilities. A third intervention educated in-school adolescents on sexual and reproductive health using a life skills curriculum. FRONTIERS and PATH provided technical assistance to all three ministries to implement the interventions. A detailed description of the OR phase is available in an earlier report. ${ }^{1}$

The OR phase included diagnostic and population-based baseline surveys and endline surveys in experimental and control locations. The endline survey measured changes in knowledge, attitudes and behaviors. Activities implemented in the OR phase were captured in standard reporting forms and entered into a computerized management information system (MIS) for analysis of outputs. The direct and indirect costs of these activities were also calculated. Table 1 below summarizes the three interventions.

\section{Intervention one: Creating a supportive environment for addressing adolescent sexual reproductive health and rights}

This community-based intervention was implemented by Ministry of Gender, Sports, Culture and Social Services (MGSCSS), through its Social Development Assistants (SDAs). Out-ofschool youth and their parents were reached by the SDAs to increase their SRH knowledge and to promote parent-child communication. The SDAs used their extensive community networks of provincial administration, women, youth and religious groups to mobilize support for the project. Through their membership of Location Social Development Committees the SDAs ensured the prioritization and implementation of ASRH in the community. KARHP sought to build on the experience and network base of SDAs to develop a supportive environment for ASRH concerns at the community level. Parents, youth, opinion leaders and religious groups were mobilized and sensitized by SDAs to support the provision of ASRH information and services.

Askew, I., J. Chege, C. Njue and S. Radeny. 2004 “ A multisectoral approach to providing reproductive health information and services to young people in Western Kenya: The Kenya Adolescent Reproductive Health Project," Washington DC: Population Council http://www.pocouncil.org/pdfs/frontiers_finalreports/kenya_karp\%20adol.pdf 
Table 1 Interventions and key activities

\begin{tabular}{|c|c|c|c|}
\hline & $\begin{array}{c}\text { Implementing } \\
\text { partners }\end{array}$ & Target population & Activities \\
\hline $\begin{array}{l}\text { INTERVENTION } 1 \\
\text { Creating a } \\
\text { supportive } \\
\text { environment to } \\
\text { address adolescent } \\
\text { sexual reproductive } \\
\text { health and rights }\end{array}$ & $\begin{array}{l}\text { Ministry of Gender, } \\
\text { Sports, Culture and } \\
\text { Social Services }\end{array}$ & $\begin{array}{l}\text { Divisional Social Development } \\
\text { assistants } \\
\text { Location Social Development } \\
\text { Agents } \\
\text { Local Chiefs } \\
\text { Religious Leaders } \\
\text { Women groups } \\
\text { Youth groups } \\
\text { Out-of-school youth } \\
\text { Parents }\end{array}$ & $\begin{array}{l}\text { Public meetings } \\
\text { (Barazas) } \\
\text { Sports } \\
\text { Song, drama } \\
\text { Peer education } \\
\text { Video shows } \\
\text { Public debates } \\
\text { Church sermons }\end{array}$ \\
\hline $\begin{array}{l}\text { INTERVENTION } 2 \\
\text { Meeting the } \\
\text { information and } \\
\text { service needs of } \\
\text { sexually active } \\
\text { adolescents }\end{array}$ & Ministry of Health & $\begin{array}{l}\text { doctors } \\
\text { Clinicians } \\
\text { Nurses } \\
\text { Public Health Technicians } \\
\text { Young people }\end{array}$ & $\begin{array}{l}\text { Setting up Youth } \\
\text { Friendly rooms } \\
\text { Provision of IEC } \\
\text { materials } \\
\text { Counseling } \\
\text { Medical Treatment }\end{array}$ \\
\hline $\begin{array}{l}\text { INTERVENTION } 3 \\
\text { Educating in-school } \\
\text { adolescents }\end{array}$ & Ministry of Education & $\begin{array}{l}\text { Guidance and Counseling teachers } \\
\text { Peer educators } \\
\text { Students } \\
\text { Head teachers/principals } \\
\text { Parents Teachers Association/ } \\
\text { school management committees }\end{array}$ & $\begin{array}{l}\text { Peer education } \\
\text { Face to face counseling } \\
\text { Debating clubs } \\
\text { Essay competitions } \\
\text { Sports competitions } \\
\text { Songs, skits and drama } \\
\text { educative video shows } \\
\text { Question Boxes }\end{array}$ \\
\hline
\end{tabular}

SDAs received training on ASRH and were facilitated to integrate $\mathrm{RH}$ within their workplans. They were also facilitated to conduct advocacy and mobilization activities within their respective communities. The SDAs recruited, trained and supervised out-of-school peer educators to reach out to their peers in the community with information about life skills. The "Tuko Pamoja" life skills curriculum was developed and used to train the peer educators, increasing ARH knowledge and rights, changing attitudes and providing skills to adopt safer sexual practices.

Local chiefs, religious leaders and women's group leaders were recruited and trained to mobilize and sensitize their respective groups. The community leaders used different forums to reach the community and the youth, including religious meetings, and community barazas (community meetings). Enter-educate approaches such as community drama and songs, video shows and sports were used. In addition, community leaders acted as counselors to young people in their congregations and allowed the peer educators to use their facilities for outreach activities.

\section{Intervention two: Meeting the information and service needs of sexually active adolescents}

This intervention was implemented through the Ministry of Health. The intervention provided SRH information and services by improving the "friendliness" of public and private clinics in order to attract adolescents seeking care. Service providers including medical doctors, clinical 
officers and nurses from public and private health facilities in the four study locations, were recruited and trained on ASRH and youth friendliness. Participating public health facilities designated youth-friendly rooms for peer education. The rooms also served as contact points for service providers to pass information and offer actual services to adolescents. Information, Education and Communication (IEC) materials were provided for distribution and for use in oneto-one counseling.

\section{Intervention three: Educating in-school adolescents}

The third intervention, implemented through the Ministry of Education, reached in-school adolescents. To mobilize school support for KARHP, head teachers, members of school management committees and members of Parents Teachers Associations were sensitized on the program's initiatives. Guidance and Counseling (G\&C) teachers were recommended receive training in facilitation skills and ARH using the Tuko Pamoja life-skills curriculum. The G\&C teachers followed a 34-hour life-skills curriculum covering the following topics: adolescence; reproduction; health relationships; peer pressure; decision making; rug and substance abuse; parenthood; STI/HIV/AIDS; life skills; sexuality and behavior; gender; sexual exploitation and violence; and others. In total, seventy-four G\&C teachers from 27 schools were trained in the intervention locations. These teachers were subsequently required to provide appropriate information and counseling to the adolescents.

The G\&C teachers recruited and trained about 600 peer educators in schools to reach their peers. Peer educators were facilitated to conducted outreach activities in schools through school debates, essay contest, educational videos, and one-on-one counseling. The peer educators were often the first contact for students requiring assistance and information. The G\&C Teachers conducted life skills training sessions for different classes and facilitated the set up of KARHP clubs as avenues for students to meet and discuss SRH. In some schools, G\&C teachers conducted ARH sessions after regular school hours, while others integrated the sessions with other subjects or in extracurricular activities. At the end of the pilot phase, each teacher had conducted an average of 12 sessions and had counseled about 26 school children.

\section{Key highlights of the pilot phase}

The three ministries successfully implemented the interventions, with a significant proportion of adolescents and parents participating. The in-school and community interventions were very effective. The health facility-based services were however not widely used. The peer educator models were largely successful in reaching adolescents with information although their sustainability was limited.

Sexual and reproductive health information provided through the life skills curriculum increased knowledge, consciousness, and communication of adolescent sexual and reproductive health issues. Endline survey findings showed increased levels of delayed onset of sexual activity, reduced number of sexual partners, reduced incidences of sexual violence, reduced levels of unplanned pregnancies and school drop-out among in-school youth, reduced reported STI cases and improved safer sexual practices. Parent-to-child discussion on SRH increased and communities became more receptive to information and dialogue about ASRH. 
Evaluation results also found increased awareness of contraceptive methods among all girls and younger boys. Large increases in knowledge of condoms, pills and injectables occurred among the youth. The community and school based interventions enhanced abstinence as a preventive behavior. Condom use for dual prevention of STIs and pregnancy became better known among adolescents. The level of awareness of specific STIs among all adolescents increased significantly. The interventions also reinforced the disapproval of premarital sex and childbearing particularly disapproval for teen pregnancies.

These outcomes were realized amidst dramatic changes that were occurring within Kenya at the time. Starting in 1999, HIV/AIDS was declared a national disaster opening doors for government campaigns and public discussion of the pandemic. All three partner ministries in KARHP independently developed ARH and HIV/AIDS initiatives at the provincial and national levels. At the same time, the Ministry of Education launched a school-based HIV/AIDS education curriculum. In 2001, the Children's Act was passed into law. The 'Adolescent Reproductive Health and Development' Policy was developed and launched (September 2003) over the same period.
- $\quad 59-72 \%$ of boys and $76-84 \%$ of girls reported never having undertaken any type of sexual activity (including kissing and touching). Among those reporting sexual experience, very few have practiced kissing or touching, with penetrative sex being the norm.

- Adolescents directly participating in the school-based activities, reported experience of all types of sexual behaviour is significantly lower than for other adolescents not exposed to the school-based intervention.

- Age at first sex among the sexually experienced showed statistically significant delays after the interventions among young people in the intervention sites, as compared to no change in the control site.

- The proportions of girls in all sites, and of boys in the intervention sites only, first having sex with someone other than a close friend decreased significantly. The proportions of girls indicating nonconsensual sex decreased over time. Secondary abstinence remains very common, with one half to two thirds of sexually active girls and boys not having sex in the previous six months, but there was no change over time in any sites.

- There were decreases over time in the proportion of unmarried girls reporting ever been pregnant. 


\section{ADAPTATION PHASE}

The positive results of the pilot phase prompted adaptation and expansion of KARHP throughout the two pilot districts of Vihiga and Busia over a 20-month period (2003 to 2005). The aims of this phase were to:

a. Gain district, provincial and national level commitment and building ministry-specific training capacities to scale-up into remaining locations in two pilot districts;

b. Review and revise materials and tools used in the pilot study;

c. Initiate inter-ministerial committees at various levels;

d. Establish costs needed to run project activities within public sector; and

e. Lobby for sustained ministry commitment.

\section{a. Gaining interest and commitment to build capacity for expansion}

FRONTIERS and PATH facilitated workshops with each of the ministries to review the OR study results and supported them to identify what could be absorbed into their respective programs. The workshops were held at national, provincial and district levels and identified a generic package of interventions for each ministry and implementation plans for each package. Practical implications of the proposed activities, expansion of the activities and all expected program challenges were explored. Based on the OR findings, each ministry identified sets of possible and cost-effective ARH interventions for expansion. At each ministry level, the following outcomes were realized:

i. The Ministry of Education decided to continue implementing the complete package of interventions as introduced in the OR phase, i.e. peer education, implementation of the life-skills curriculum, guidance and counseling, school health clubs and inter-schools activities. These were extended to all schools in the two pilot locations. Schools were encouraged to integrate ARH into regular school syllabus by the ministry. Guidance and counseling was recognized as a formal subject in the school timetable. Additionally, funds from the district education office budgets were approved to support revival of school KARHP activities and ministry supervision systems for ARH.

ii. The Ministry of Health decided to sustain the clinic based KARHP activities but incorporated a community-based health outreach program. This outreach program involved Public Health Technicians and Community Health Workers. The health facility component was managed by clinic based nurses and doctors. District Health Management Teams (DHMTs) were mobilized and sensitized to oversee the implementation of these activities.

iii. The Ministry of Gender, Sports, Culture and Social Services chose to continue implementing the complete sets of interventions tested in the OR project. Adolescent reproductive health was integrated into district work-plans and in the 5-year national youth policy implementation plan. Out of school peer educators were linked to income generating activities and micro-credit programs to reduce their attrition. They also 
received training sessions on entrepreneurial skills and empowerment that were provided alongside the life skills curriculum.

Intense advocacy was conducted with each ministry at the provincial and national levels to encourage government buy-in and ownership. The implementation experiences were also used by the ministries to review work plans, adolescent RH and HIV/AIDS prevention policies and guidelines.

\section{b) Revision of materials and tools}

Training materials and monitoring tools tested in the OR phase were revised based on experiences and evaluation results. Workshops held with each ministry at provincial and district levels identified sets of materials and tools needed for expansion. The revision of materials took into considerations specific ministry experiences. Some materials which were considered to be too technical for location or community staff were simplified to accommodate the audience. The possibility of integrating the tools in the monitoring and evaluation systems of the respective ministries was also considered.

Together with the ministries, FRONTIERS and PATH developed three sets of "How To" manuals that provided a comprehensive step-by-step instructions and tips on how to develop and implement successful ARH and HIV/AIDS prevention activities. Additionally, all the three training curricula and other training materials (such as job aids and other support materials for the three ministries) were revised to include their experiences and to become audience specific. The training process was reviewed to accommodate actual experiences of the ministries. A cascade training model was adopted. Master trainers at the provincial and district levels were inducted to train divisional and location ministry personnel to implement the program.

The reporting tools for the OR study had been criticized for being too many, too long, and too cumbersome to manage. They were multiple-stage, weekly, bi-monthly and monthly reporting tools. The tools were reduced to a single monthly, user-friendly reporting tool, in line with ministry expectations. District and divisional level planning committees reviewed and refined the tools to harmonize them with existing ministry protocols. A simplified single monitoring form was developed, structured around relevant data for both ministry and PEPFAR reporting. The form recorded planning, training and sensitization activities as well as service delivery data (see Appendix 1).

The distribution and completion of the form was consistent with the organizational charts of each ministry. In the MOE, the form was to be completed by the trainer/facilitator (e.g. Religious Leaders, SDAs, G \& C Teachers) on a monthly basis and submitted to the location heads. The MOGSCSS form was to be completed by the TAC tutors, Social Development Assistants (SDAs). The MOH forms were completed by Public Health Technicians (PHTs). The forms were collected at the district level by FRONTIERS field staff. The distribution of fresh forms followed similar channels. A revised centralized MIS database was created that provided an integrated comprehensive data collection structure for monitoring KARHP activities. This new system was user friendly and adaptable to any data analysis. 


\section{c) Initiating Inter-ministry linkages committees at various levels}

During the OR phase, each ministry addressed one component of the program. Based on the pilot experience, there was need to harmonize the operations of the three ministries. This was achieved through creating inter-ministry committees (Figure 1). The committees were based on existing government supervisory structures. At each level of government, a contact person charged with day-to-day coordination of KARHP activities was identified. The person liaised with the next level of government and other collaborating ministries. Together the liaison officers from the three ministries facilitated by PATH and FRONTIERS held regular quarterly meetings at provincial, district, divisional and location levels. The committees supervised and coordinated KARHP implementation.

\section{Figure 1 KARHP Multi-Sectoral Committee structures}

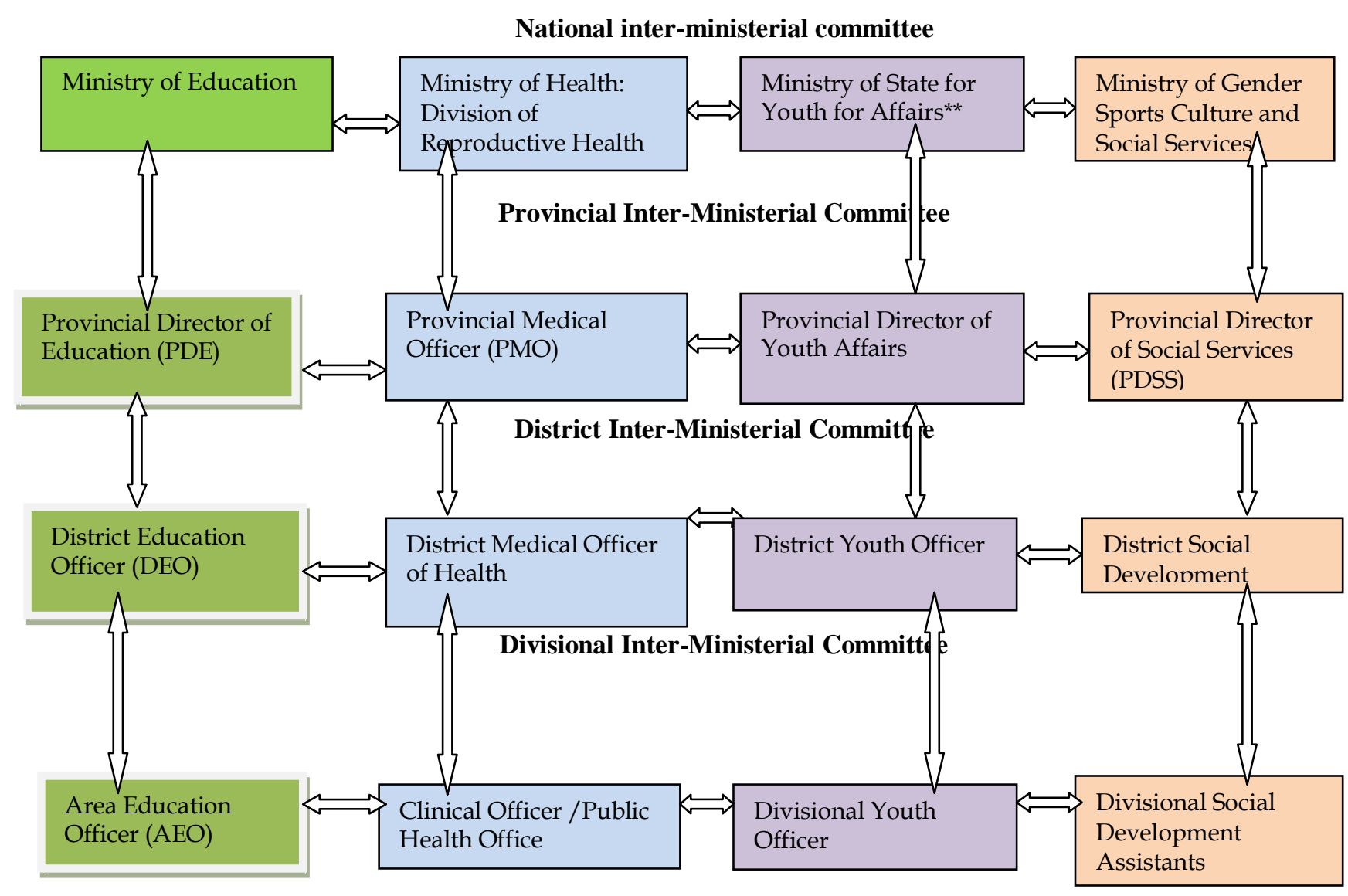

*The Ministry of Youth Affairs was created in 2006. It took over most of youth activities previously handled by the MGSCSS. 


\section{d) Determining the costs needed to routinely implement activities within the public sector}

A common question raised by the Ministries was the cost of running the program. Cost analyses for all the project phases were done including: planning/preparation of project interventions; training and introduction of interventions; and implementation of interventions, and monitoring and supervision.

The total costs of the three intervention components over the two and a half years of planning, introduction and implementation was approximately $\$ 154,374$. The school based intervention had the highest overall costs. ${ }^{2}$ The single most expensive activity was supervision and monitoring, which was $55 \%$ of total costs followed by training. No costs for implementation of the clinic based services were included because the clinical staff did not record time spent on KARHP activities.

Costs of developing and implementing the interventions within the framework of the OR study were dominated by technical assistance provided from PATH. However, for various reasons the costs were expected to be substantially lower in scaling up phase by government ministries. One, the structures and initial capacity had already been created and needed not be carried out again particularly in development and planning program activities. Two, the interventions themselves, including training programs, life skills curricula, and IEC materials had already been designed and this would not be repeated. Three, the expected costs would be shared with government and were for replication only. ${ }^{3}$ Costs for expanding interventions within the pilot districts by the MOE and MGSCSS were computed.

\section{Estimating the cost for the MOE to expand interventions within pilot districts:}

Costs were allocated for each activity of the project and extrapolated over a period of five years. Several assumptions were made to deduce these costs.

- A training model had already been developed and put in place

- Planning activities already conducted through the district education office in OR needed not be replicated.

- Core ToT teams would train G\&C teachers in new schools at least for the first two years of project expansion.

- Monitoring and supervision activities would be integrated within the existing district infrastructure and absorbed within existing district budgets at no additional cost

- Peer educators would be trained continuously (i.e. every year) to replace those leaving at no additional cost.

It was estimated that the annual cost of expanding the project to cover new schools within the pilot districts would require an additional KShs 6,218 per school during the first year of expansion (or $1.8 \%$ increase in per school budget allocation). Table 2 below shows the anticipated costs to the Ministry of Education over a five-year period. In total, each school required an estimated Kshs 16,416 (\$237.91) during the first year of scaling up and about 50\% of these costs were to be incurred on capacity building (training intervention personnel and ministry ToTs), and 39\% incurred on organizing and conducting planning meetings. 
Table 2: Cost to MOE to expand the ARH over a period of 5 years

\begin{tabular}{|c|c|c|c|c|c|c|}
\hline \multirow{2}{*}{ ACTIVITIES } & \multicolumn{6}{|c|}{ Additional cost of expansion per school (Kshs) ${ }^{4}$} \\
\hline & Year 1 & Year 2 & Year 3 & Year 4 & Year 5 & Total \\
\hline \multicolumn{7}{|c|}{ PHASE I: PLANNING } \\
\hline \multicolumn{7}{|l|}{ Preparatory Activities $^{5}$} \\
\hline \multicolumn{7}{|c|}{\begin{tabular}{|c|c|} 
TRAINING AND INTRODUCTION OF INTERVENTIONS & 1 \\
\end{tabular}} \\
\hline Training of Trainers (ToTs) ${ }^{7}$ & & & 2,875 & & & 2,875 \\
\hline Training of G\&C Teachers & 6,218 & & & 7,406 & & 13,624 \\
\hline \multicolumn{7}{|l|}{ Training of Peer Educators ${ }^{8}$} \\
\hline \multicolumn{7}{|c|}{ IMPLEMENTATION OF ACTIVITIES AND MONITORING } \\
\hline \multicolumn{7}{|c|}{\begin{tabular}{|l|l|l|l|l|} 
Monitoring and supervision & & & &
\end{tabular}} \\
\hline \multicolumn{7}{|l|}{ Activity implementation ${ }^{9}$} \\
\hline Total additional cost per school per year & 6,218 & $\mathbf{0}$ & 2,875 & 7,406 & $\mathbf{0}$ & 16,499 \\
\hline \% Change in annual budget per school & $1.8 \%$ & $0 \%$ & $0.7 \%$ & $1.8 \%$ & $0 \%$ & $\mathbf{0 . 8 \%}$ \\
\hline
\end{tabular}

\section{Estimating the cost for MGSCSS to expand activities within pilot districts:}

The costs were assessed for activities that reached youth, parents and other community members. Costs were allocated per location for each activity of the project and extrapolated over a period of 5 years. Several assumptions were made to work out these costs:

- Training model developed and put in place,

- Certain activities already undertaken in OR phase needed not be replicated such as national, district and divisional stakeholder meetings,

- The same core ToTs from the ministry who have already been trained would be used to train social development assistants at least for the first two years of project expansion;

4 Figures adjusted to account for inflation: Average inflation rate use for six years (1998-2003) = 0.6\%(source- economic survey 2003 -CBS

5 Meetings held to identify an "adolescent reproductive health and HIV/AIDS intervention package" to be institutionalized by each ministry (i.e. those activities from KARHP that are cost-effective and deemed feasible by each ministry), developing operational guidelines manuals for implementing each ministry-specific intervention package, revising the Life Skills Education Curriculum to including changing and emerging issues and the Facilitator's Manuals etc. This expansion and institutionalisation phase began in October 2003 to date (Feb 2005)

6 Building the technical capacity of ministry staff to sustain implementation of the adolescent reproductive health and HIV/AIDS intervention package in the four experimental locations and to introduce the intervention package into the two control location (in Vihiga and Busia districts). It is important to note that the training given during this phase was essentially NONRESIDENTIAL to facilitate sustainability. Training of ToTs, intervention personnel and peer educators (trained by core ToTs ) took about 8 months (May - Dec 2004)

7 The ministry core trainers already trained will be used to train others in the process of scaling up the project.

8 There are no direct costs that were incurred in training peer educators (in-house activity).

9 Service delivery by intervention personnel is an on-going activity with no direct costs (labor cost for intervention personnel is fixed) except for materials and supplies. Activities implemented include sessions by G\& C teachers, peer educators and Religious leaders 
- Monitoring and supervision activities would be integrated within the existing district infrastructure and therefore absorbed within the existing district budgets, and

- In expanding the project to new locations, peer educators would be trained every two years.

The project expansion in the pilot amounted to Kshs 517,638 per location annually ${ }^{10}$ (or $\$ 6,900$ ). The ministry's contribution had been in the form of labor and infrastructure. To expand the project to cover more locations within pilot sites required the ministry to increase spending per location by about $3 \%$. Over a five-year period, the additional budgetary requirements would amount to Kshs $197,590(\$ 2,635)$ or a $47 \%$ increment in per location funding (see Table 4$)$. The expansion to new locations within the pilot districts took advantage of the previous investments of resources in planning for the intervention, development of training materials and capacity building. To expand the project to new sites outside the pilot districts, the ministry would have to increase its recurrent budget (non-wage) per location by approximately seven times (more than its current spending per location) representing a $739 \%$ increment in per location spending.

Table 4: Estimated costs for MGSCSS to expand ARH over five years

\begin{tabular}{|l|c|c|c|c|c|c|}
\hline \multirow{2}{*}{ Activities } & \multicolumn{5}{|c|}{ Additional cost of expansion per Location (Kshs) } \\
\cline { 2 - 7 } & Year1 & Year 2 & Year 3 & Year4 & Year 5 & Total \\
\hline Phase I: Planning of interventions & & & & & & \\
\hline Preparatory and other planning activities & & & & & & \\
\hline $\begin{array}{l}\text { Phase II: Training and introduction of } \\
\text { interventions }\end{array}$ & & & & & & \\
\hline Training of Trainers & & & & & & \\
\hline Training of intervention personnel & & & 172,566 & & & 172,567 \\
\hline Training of Peer Educators & & & 10,563 & & & 10,563 \\
\hline $\begin{array}{l}\text { Phase III: Implementing Activities and } \\
\text { Monitoring }\end{array}$ & & & & & & \\
\hline Supervision \& Monitoring & & & & & & \\
\hline Activity implementation & 2,565 & 2,719 & 2,882 & 3,055 & 3,239 & 14,460 \\
\hline Total annual additional cost per location & 2,565 & 2,719 & 186,012 & 3,055 & 3,239 & 197,590 \\
\hline MOGSCSS budget per location & 74,267 & 78,723 & 83,446 & 88,453 & 93,760 & 418,649 \\
\hline $\begin{array}{l}\text { Percentage change in annual budget per } \\
\text { location }\end{array}$ & $3 \%$ & $3 \%$ & $223 \%$ & $3 \%$ & $3 \%$ & $47 \%$ \\
\hline
\end{tabular}

10 According to the recurrent budget estimates for 2003/004, there are about 1,129 locations in the country

11 Figures adjusted to account for inflation: Average inflation rate use for six years (1998-2003) $=0.6 \%$ (source- economic survey 2003 -CBS 
e) Lobbying for sustained ministry commitment through mainstreaming activities in work plans and budgets

FRONTIERS and PATH held consultative and briefing meetings with ministry officials at all levels of government. The meetings discussed programmatic and financial implications of absorbing interventions, lobbied the ministries to buy in and own KARHP and explored costs with a view of making them part of ministries recurrent budgets (non-wage). Subsequently, the ministries received support to incorporate selected KARHP activities within national, provincial and district schedules.

All ministries decided to adopt the 'cascade' non residential training approach to lower the average costs. They also recommended incorporating ARH content into existing pre- and inservice training materials for teachers, social workers and health worker. KARHP curricula were adopted. Ministry of Education funded the development of a National Guidance and Counseling curriculum and policy, and requested FRONTIERS and PATH to provide technical assistance. Discussion with the ministries also resulted in recommendations to sensitize and brief treasury officials from Ministry of Finance to be able to allocate funding to the ministries for ARH. Briefing papers were prepared and meetings were held with treasury. 


\section{SUSTAINING AND SCALING UP}

The evaluation results continued to draw enthusiasm from the ministries who recommended that the program be scaled up to all eight districts of Western Province. FRONTIERS and PATH extended technical assistance to the ministries to plan for the scale-up. Work plans were drawn and activity costs estimated. Technical capacity of ministry staff was built to implement and supervise the interventions. The objectives of scaling up were:

- To facilitate the ministries institutionalization of the successful and cost effective OR interventions

- To facilitate the ministries replication of the interventions throughout Western Province

- To facilitate the ministries review of their policies, standards and guidelines concerning adolescent reproductive health and HIV/AIDS prevention and, if necessary, to revise them accordingly.

During scale up, FRONTIERS and PATH used a highly participatory process, engaging local stakeholders, government officials and teams of local implementers to reach a common understanding of expected outcomes. A provincial field office was opened and maintained by PATH and FRONTIERS. The field staff facilitated collaboration and implementation of activities by:

- Maintaining regular contact with stakeholders;

- Mobilizing the communities;

- Advocating and planning meetings with stakeholders;

- Encouraging discussions on ARH; and

- Encouraging buy in and ownership of the program.

National-level advocacy was stepped up during this period to strengthen support and create a favorable ARH environment. The expansion model was based on three main strategies:

- Institutionalization of capacity,

- Strengthening of inter-sectoral collaboration, and

- Strengthening monitoring and record keeping.

\section{a) Institutionalization of capacity}

Day-to-day program activities during expansion in Western Province were financed by FRONTIERS and PATH. Activities supported included: planning, introduction of the interventions, capacity building for ministry staff and implementation. Core training and supervision teams within each ministry received training using a layered approach of skills transfer in order keep costs low and shared with the ministries. 
The layered approach for capacity building followed existing government supervisory structures where the senior ministry staff would train and supervise those below them. National ministry officials were inducted as "master trainers", who then trained provincial and district officials as "core trainers". The core trainers were responsible for training the divisional and location ministry officers as illustrated in Table 5 below. This cascade-training model was strengthened at every level by the presence of a master trainer or a core trainer from the higher level; when possible, a trainer from FRONTIERS and PATH attended the training for quality assurance. The underlying assumption was that inducting ministry staff on ARH would enable them to better plan and integrate ARH into their routine activities. Throughout the expansion, ministry staff was facilitated to develop detailed work-plans for each ministry, with clear indications of the resources required and costs implied for the activities. ${ }^{12}$

Table 5 Cascade training model for ministries

\begin{tabular}{|c|c|c|c|c|}
\hline \multirow[b]{2}{*}{ Ministry } & \multicolumn{4}{|c|}{ Who was trained } \\
\hline & $\begin{array}{l}\text { Master } \\
\text { trainers }\end{array}$ & Core trainers & Division staff & $\begin{array}{c}\text { Location/community/ } \\
\text { school }\end{array}$ \\
\hline $\begin{array}{l}\text { Ministry of } \\
\text { Education }\end{array}$ & $\begin{array}{l}\text { National } \\
\text { officer, } \\
\text { Department } \\
\text { of Guidance } \\
\text { and } \\
\text { Counseling }\end{array}$ & $\begin{array}{l}\text { Provincial education } \\
\text { officer/deputy } \\
\text { Provincial Quality Assurance } \\
\text { and Supervisory officers } \\
\text { District Education } \\
\text { Officer/Deputy } \\
\text { District Quality Assurance an } \\
\text { Supervisory Officers }\end{array}$ & $\begin{array}{l}\text { Area Education } \\
\text { Officers } \\
\text { Teacher } \\
\text { Advisory Centre } \\
\text { Tutors }\end{array}$ & $\begin{array}{l}\text { Head teachers, Chairmen } \\
\text { of school management } \\
\text { committees, Board of } \\
\text { Governors, Guidance } \\
\text { and Counseling teachers } \\
\text { Per educators }\end{array}$ \\
\hline $\begin{array}{l}\text { Ministry of } \\
\text { Health }\end{array}$ & $\begin{array}{l}\text { Program } \\
\text { Officer, } \\
\text { ASRH, } \\
\text { Division of } \\
\text { Reproductive } \\
\text { Health, } \\
\text { Program }\end{array}$ & $\begin{array}{l}\text { Provincial Medical Officer } \\
\text { (PMO) the Provincial Public } \\
\text { Health Officer (PPHO), } \\
\text { Provincial Reproductive Health } \\
\text { Coordinator District Medical } \\
\text { Officer Of health (MOH), } \\
\text { District Public Healthy } \\
\text { Technician (DPHO). }\end{array}$ & $\begin{array}{l}\text { District Public } \\
\text { Health } \\
\text { Divisional Pubic } \\
\text { Health Officers } \\
\text { (DPHO). }\end{array}$ & $\begin{array}{l}\text { Location Public Health } \\
\text { Technicians and } \\
\text { Community Health } \\
\text { Workers, clinicians, } \\
\text { nurses }\end{array}$ \\
\hline $\begin{array}{l}\text { Ministry of } \\
\text { Gender } \\
\text { Sports, } \\
\text { Culture and } \\
\text { Social } \\
\text { Services }\end{array}$ & $\begin{array}{l}\text { Department } \\
\text { of Youth } \\
\text { affairs }\end{array}$ & $\begin{array}{l}\text { Provincial Director of Social } \\
\text { Services (PDSS), District } \\
\text { Social Development Officers } \\
\text { (DSDOs }\end{array}$ & $\begin{array}{l}\text { Divisional } \\
\text { Social } \\
\text { Development } \\
\text { Advisors } \\
\text { (DSDAs), and } \\
\text { all Social } \\
\text { Development } \\
\text { Assistants } \\
\text { (SDAs }\end{array}$ & $\begin{array}{l}\text { location social } \\
\text { development committees } \\
\text { (SDC), Out of school } \\
\text { youth groups, religious } \\
\text { leaders, chiefs }\end{array}$ \\
\hline
\end{tabular}

12 The development of the costing tool and its application was the responsibility of FRONTIERS, with active participation by district and PATH staff to ensure that it is appropriate for this situation. Special thanks goes to Isaac Lamba, Nzoya Munguti (Health Economist) and Rick Homan (FHI) for backstopping this exercise. 
Due to the large numbers of schools in the expansion districts, the MOE decided to include only one-third of all primary and secondary schools in the eight districts. The rationale behind this strategy was to build adequate capacity in each district through introducing the model into onethird of the schools and to facilitate roll-out to the remaining schools by the ministry itself. Oneday sensitization meetings were conducted for head teachers and a member of School

Management Committee or Board of Governors, to facilitate and support for KARHP. This was followed by a five-day residential training session for $\mathrm{G} \& \mathrm{C}$ teachers.

Each five-day teacher training session had 20-25 participants, facilitated by 3 core trainers. The course included 12 sessions (see box 5) and was intended to enable teachers to use the KARHP curriculum within their schools. Again to keep costs low, schools and Teacher Training colleges with relatively better amenities were used as training venues. This provided adequate space for several training sessions to be conducted with different groups simultaneously.

After training, the G\&C teachers were supported to recruit, train and supervise peer educators from among their pupils. Peer educators were among class pupils with good interpersonal and leadership skills. Ideally, each class was to represent a specific age set. At least five peer educators were recruited per class of 50 , giving a total of 8,800 peer educators from 440 schools covered in the expansion phase in western province.

In the MGSCSS, a team of officials comprising of staff from the national office, the Provincial Director of Social Services (PDSS) and the District Social Development Officers (DSDOs), were recruited and trained as core trainers. This team then trained Divisional Social Development Advisors (DSDAs) and all Social Development Assistants (SDAs) in each district in a three-day training session.

\section{Box 5 Five-Day Training Session for Teachers}

The goal of this five day Workshop was to provide knowledge and skills to enhance provision of comprehensive and integrated services to youth. It aimed at enabling participants be able to:

1. Communicate effectively and comfortably with adolescents about sexuality and reproductive health.

2. Assist youth to make informed reproductive health decisions Provide quality and youth friendly reproductive health services

3. Use the methodology of the workshop for the training of other.

Emphasis is placed on Interpersonal Communication and Counselling Skills. The module assumes that the participants are sufficiently familiar with certain topics, such as Family Planning Methods, sexually transmitted diseases including HIV/AIDS.

Session 1 Adolescent Reproductive Health

Session 2 Adolescent Sexuality and Sexual Behaviour

Session 3 Communication Skills - Providing Services to Youth

Session 4 Context of Interpersonal Communication

Session 5 Effective Interpersonal Communication Skills

Session 6 Counselling Skills

Session 7 Attending Skills for Counselling

Session 8 Reflections Summary in Counselling

Session 9 Challenging Moments in Counselling

Session 10 Evaluating Counselling

Session 11 Using Visual Aids for Counselling

Session 12 Action Plans and Course Evaluation

Twelve training sessions were required to train 239 DSDAs and SDAs, with three trainers facilitating each session of 20-25 participants. The SDAs also worked closely with members of the location development committees (SDC). SDC is made up of at least 10 members with representation from youth, community leaders, religious leaders, women group leaders and people with disabilities. These committees then mobilized and sensitized communities on ARH and HIV prevention. 
The core trainers in the Ministry of Health included: a national official from the Division of Reproductive Health, the Provincial Medical Officer (PMO), the Provincial Public Health Officer (PPHO), Provincial Reproductive Health Coordinator and the District Public Health Officers (DPHO). The trainers then trained and supervised the Divisional Pubic Health Officers (DPHO) and Public Health Technicians (PHTs) in each district expected to provide adolescent reproductive health information and services and referrals where possible. Each training session had twenty five participants facilitated by three core trainers.

\section{b) Strengthening of inter-sectoral collaboration}

During the expansion phase, provincial, district and divisional teams were created and mandated to oversee the implementation of KARHP activities. These teams were formed by contact persons from each of the three ministries. In some instances, stakeholders from religious groups and provincial administration were co-opted members. Inter-ministry committees followed government structure (see Figure 1 above) to enhance harmony. The committees met every quarter to review progress made, discuss challenges and provide way forward for KARHP implementation. Initially, the meetings were facilitated by FRONTIERS and PATH. Later, this role was taken over by the three ministries who chaired meetings on a rotational basis each quarter. Notable contributions of the committees to KARHP institutionalization included the decision to share training facilities, resources and conduct joint supervision of activities. Whenever possible, FRONTIERS and PATH provided technical assistance in planning and budgeting for these activities.

\section{c) Strengthening monitoring and record keeping}

The Management Information Systems (MIS) modified in the adaptation phase was used to collect program data. The MIS comprised of ministry specific activity forms, which were filled after each KARHP event. The forms gathered data on specific activities, target audience and topics, number of people reached, services received, feedback and referrals, other collaborators and observations about the activity. The forms were submitted monthly by the grassroots' implementers through ministry channels and collected by FRONTIERS and PATH field coordinators at the district level. The data were then reviewed by the field office for quality, entered into EPI-INFO and forwarded to FRONTIERS's Nairobi office for analysis. The outputs were used for donor reporting and also shared with the ministries to evaluate the program success and improve program implementation.

\section{d) Government input in expansion and utilization of the model}

Government ministries played a key role as implementers and facilitators in rolling out KARHP. They were responsible for integrating ARH activities within their routine procedures, coordinating and facilitating all KARHP activities within their departments. Among the key functions they played were:

i) Recruitment and training of implementers: Each ministry identified staff to be trained as KARHP implementers from selected divisions and locations. Most of them came from regions identified with poor sexual and reproductive health indicators such as high drug use rate, teen pregnancy and low SRH information levels. 
ii) Implementation and integrating ARH activities into the routine ministry programs: Trained government officers were responsible for implementing KARHP activities within their jurisdiction. They ensured that these activities were well articulated in their work plans. At the lowest levels, they sensitized communities, religious leaders, parents and youth to support and adopt the program. In schools, KARHP was integrated into existing school activities - in regular class lessons, in debates, drama, essay writing, KARHP clubs, and booths set up during sports and music events. At the community level, KARHP was integrated into religious sermons, public meetings and Barazas addressed by government officials. At the health facility youth friendly information and services were offered.

iii) Coordination, monitoring and reporting: The coordination of KARHP activities within each ministry followed government structure. National office was responsible for overall coordination and supervision. The provincial head coordinated and supervised the province and the districts. Inter-ministry committees aided in joint coordination and supervision.

iv) Advocacy and resource mobilization: In each ministry the contact person at each level spearheaded discussions to mobilize their departments to support KARHP activities. They identified opportunities for integration of ARH within departmental policies, guidelines and budgets. KARHP was discussed in key decision-making organs such as District Development Committees, Provincial and District Education Board meetings. In Western Province the Provincial Education Board ratified the expansion and funding of KARHP to all schools in the province. Similar approaches were taken by MGSCSS and MOH. 


\section{RePlicating KARHP in OThER ProvinceS}

The successful expansion of the KARHP in Western Province inspired donors and ministries to support its roll-out nationally. The program was first introduced in two pilot districts per province in the first year, followed by expansion to the remaining districts in the second year using the capacity developed in the two pilot districts. The replication strategy built on approaches used during the scaling-up phase including:

i. Conducting introductory and planning meetings with provincial and districts heads for buy-in and support,

ii. Building ministry capacity at provincial level and two pilot districts,

iii. Sharing costs with ministries during training, implementation and supervision

iv. Setting up management information systems to collect data for use by ministries and for donor reporting,

v. Initiating inter-ministerial committees and facilitating quarterly meetings, and

vi. Continued advocacy at national, provincial and district levels for acceptance, buy-in and ownership.

During this phase, two levels of replication occurred. First, KARHP was replicated in Nyanza and Eastern provinces (June 2006 to May 2007) and then into Nairobi and Central provinces (June 2007 to May 2008). Each level planned a thirteen month replication adopting similar strategies as applied in the scale up of KARHP in Western Province.

This phase began with consultative meetings conducted with national, provincial and district heads in four provinces. The introductory meetings discussed the program, assessed the uniqueness of each province, selected pilot districts and prepared a plan for replication. In most cases, replication begun with participation in developing annual operations plans to ensure KARHP activities were prioritized and integrated in ministry work plans.

FRONTIERS and PATH maintained field offices in the replication provinces to support the ministries. The ministries set up inter-ministry committees to coordinate and monitor KARHP implementation. As was the case in the Western Province, the initial activities and inter-ministry meetings were facilitated by FRONTIERS and PATH, but eventually taken up by the ministries on a rotational basis. During the first level of replication, FRONTIERS worked in Eastern Province while PATH facilitated activities in Nyanza Province. In the second level of replication, FRONTIERS facilitated all activities in Nairobi and Central Provinces.

In 2006, USAID/Kenya released a five-year funding mechanisms for all provinces under the AIDS Population and Health Integrated Assistance Program (APHIA II). APHIA II partners supported ASRH by working closely with government ministries, targeting communities and schools to promote healthy behaviors and the uptake of health services. In many ways, APHIA II provided an excellent opportunity for replicating KARHP model to other provinces. RONTIERS and PATH worked closely with regional APHIA II consortia to promote adoption, adaptation and utilization of the KARHP model in Nyanza and Eastern provinces. In Nairobi and Central provinces, FRONTIERS successfully initiated discussions and briefing meetings with PATHFINDER/APHIA II in the two provinces to adopt and utilize the model. 
The replication phase continued to receive support from the ministries. In April 2007, the MOE allocated Kshs 2.1 million to roll-out the program to 600 schools in Nyanza and Eastern provinces. In total, 12 districts benefited from this expansion including Nyamira, Homabay, Kuria, Suba, Siaya and Bondo in Nyanza Province and Tharaka, Meru South, Meru North, Kitui, Mwingi and Makueni in Eastern Province. A total 264 (246 G\&C teachers and 18 MEST officials) were trained in Nyanza Province and 238 (225 G\&C teachers and 13 MEST officials) in Eastern Province. Population Council and PATH provided materials (Tuko Pamoja manual) and technical assistance in planning and facilitating expansion. In April 2008, the Ministry of Education further approved KSH.1.5 million to expand KARHP to four districts in Coast Province while the Ministry of state for Youth affairs trained 70 tutors from youth polytechnics nationally.

At the national level, FRONTIERS continued to conduct advocacy activities to ensure that the ministries include ARH in their annual operations plans, budgets, policies and guidelines. The development of the youth friendly service guidelines and a national ARH training service provider's manual by $\mathrm{MOH}$ were achieved through this effort. Support was extended to $\mathrm{MOH}$ to review and finalize a national peer educators' trainers manual. MGCSS has used KARHP monitoring form to monitor and supervise own staff at the division level. Ministry of Education received support in developing the national Guidance and Counseling Curriculum and Policy framework. 


\section{SUMMARY OF CHALLENGES AND LESSONS LEARNED}

From piloting to replication, the three ministries received substantial technical assistance from FRONTIERS and PATH to successfully sustain, institutionalize and scale-up KARHP. Working with the ministries ensured integration of activities within routine operational plans, protocols and policies. It has also ensured ownership and prioritization of ARH issues including budgetary allocation from government. Key to the ministry's adoption of the KARHP was their initial involvement in the planning and design of the program. The use of OR evidence was also important to improve and adapt the interventions within existing government structures. The ministries' priority concerns were the implied costs to integrate, and how to implement and sustain KARHP activities within the overall government framework and not disrupt their government funding. The experience of piloting, scaling up and replication of KARHP has illustrated that this is feasible.

A key component is the importance of building partnerships that support and strengthen community action for adolescent reproductive health. This enhanced acceptance and ability to negotiate with the community on how best to adapt interventions in the most culturally acceptable way. Dissemination of evidence collected in pilot study together with advocacy at the local and national level to communities, stakeholder and government ministries enhanced buy in and ownership. It also helped defined levels of partner involvement. Local support and national teams strengthened implementation, coordination, monitoring and impact of the interventions.

The multi-sectoral collaboration proved efficient and effective in skills transfer. Use of cascade training core groups of master trainers fitted well within government structures improving on expertise to expand the interventions. They particularly enhanced program implementation and supervision.

Partnerships created helped identify opportunities for leveraging of resources and funding. This worked very well in the scaling up and replication phases, where the government funded expansion. Government ministries were able to talk to each other and share other resources, such as training facilities and joint supervision, hence minimizing expansion cost. The success of the program benefited from the long-term commitment by FRONTIERS and PATH as well as donor support from UASIAD/PEPFAR.

Despite the overall success of working with public sector, there were some challenges faced. These included:

i) High staff turnover initially and attrition rates of out of school peer educators. Transfers of trained teachers without proper handing over in schools interrupted the implementation of the program. The MGSCSS was hit by staff shortages at the location level.

ii) Technical assistance to partner ministries was required in implementing the project activities including planning and design, capacity building, budgeting, integration of ARH within routine work plans and policies, and monitoring and supervision of project activities.

iii) Resource availability and complex budgeting and planning system within the public sector. 
iv) Countering entrenched beliefs in communities.

v) Transitions in responsibilities and initiative from pilot project mentality to a ministryowned program and from donor dependency to ministry support.

vi) Difficulty in estimating costs, especially in the pilot phase, due to lack of proper data management and delays in submission of reports.

In conclusion, multi-sectoral approaches in addressing ASRH have been proved effective in improving adolescent sexual and reproductive health knowledge and behavior. For these efforts to be sustainable, partners should be involved and willing to integrate activities within their respective programs, share costs and create a favorable policy and legislative environment. It would however be more valuable to evaluate the continuity, support and impact of KARHP on sustained adolescents health services and behaviors in provinces that have implemented the program over the years. 


\section{APPENDIX 1}

KENYA ADOLESCENT REPRODUCTIVE HEALTH PROJECT (KARHP)

MINISTRY OF GENDER, CULTURE AND SOCIAL SER VICES ACTIVITY FORM

1) Type of respondent completing form*

2) Name of respondent

3) District:

2) Name of
4) Division

5) Location/Zone:

\begin{tabular}{|c|c|c|c|c|c|c|c|c|c|}
\hline \multirow[t]{2}{*}{ Lno } & \multirow[t]{2}{*}{ 7) Activity** } & \multirow[t]{2}{*}{ 8) Time spent (hrs) } & \multirow[t]{2}{*}{ 9) Date Conducted } & \multirow{2}{*}{$\begin{array}{l}\text { 10) Nature of Group } \\
\text { Involved (Admin, } \\
\text { parents, youth, etc) }\end{array}$} & \multicolumn{2}{|c|}{$\begin{array}{l}\text { 11) No. of participants } \\
\text { involved }\end{array}$} & \multirow[t]{2}{*}{ 12) Topics Covered**** } & \multirow[t]{2}{*}{$\begin{array}{l}\text { 13) No. of other trainers } \\
\text { /facilitators involved }\end{array}$} & \multirow{2}{*}{$\begin{array}{l}\text { 14) Any } \\
\text { Referrals } \\
\text { Yes /No }\end{array}$} \\
\hline & & & & & a) Male & b) Female & & & \\
\hline \multicolumn{10}{|c|}{ metsos } \\
\hline \multicolumn{10}{|l|}{2} \\
\hline \multicolumn{10}{|l|}{3} \\
\hline \multicolumn{10}{|l|}{4} \\
\hline \multicolumn{10}{|l|}{5} \\
\hline \multicolumn{10}{|l|}{6} \\
\hline \multicolumn{10}{|l|}{7} \\
\hline \multicolumn{10}{|l|}{8} \\
\hline \multicolumn{10}{|l|}{9} \\
\hline \multicolumn{10}{|l|}{10} \\
\hline \multicolumn{10}{|l|}{11} \\
\hline \multicolumn{10}{|l|}{12} \\
\hline 13 & & & & & & & & & \\
\hline
\end{tabular}

Entry No.1) is to be selected from Key Column B below.

Entry No.7) is to be selected from Key Column A below

Key.

\section{A) Possible Activities*"}

1. Group Discussions

2. Outreach Meetings

3. Individual Meetings

4. Counseling

5. Barazas

6. Video Shows

7. Recruitment of Peer Educators

8. Training of Peer Educators

Other (please specify:

\section{B) Type of trainer*}

1. . Religious Leader

2. .Social Development Assistant

3. .G \& C Teacher

4. .In school Peer Educator

5. Out of school, Peer educator

6. Out of school youth group leader

7. TAC Tutor

8. PHT

9. Other

\section{C) Possible Topics***}

STI infections (STIs)

Relationships

3. Drugs \& Substance Abuse

4. Communication Skills

5. Teenage Pregnancy

6. Contraceptive Use

7. Abortion

Sexual Violence

. Assertive Skills

0. Other (specify)
Provide reasons for referral(s) and state facility(ies) referred to: 
KENYA ADOLESCENT REPRODUCTIVE HEALTH PROJECT (KARHP)

MONTHLY ACTIVITY FORM

Please provide any other details you wish to report (Meetings (eg. who were involved, what topics were discussed and what were the outcomes or conclusions?) 